\title{
A prática lexicográfica e a equivalência no dicionário bilíngue
}

\section{The lexicographical practice and the equivalence on bilingual dictionary}

Rosana Budny

Universidade Federal da Grande Dourados (UFGD), Dourados / Brasil ro.budny@uol.com.br

Resumo: $\mathrm{O}$ artigo reflete sobre a prática lexicográfica e a problemática da equivalência em dicionários bilíngues, buscando, nos pressupostos teóricos da Lexicografia $\mathrm{Bi} /$ Interlíngue, embasamento para melhor entendimento da questão. $\mathrm{O}$ estudo objetiva dar a conhecer os vários tipos de correspondência que se podem almejar na tradução de unidades léxicas de uma língua A para uma língua B (WELKER, 2004; HARTMANN, 2007; WERNER; DURÃO, 2012) e apresentar algumas características vistas pelos olhares de disciplinas da Linguística Aplicada. Acredita-se que o artigo pode ajudar a esclarecer o assunto que, entre os estudiosos da área, está longe de um consenso. As reflexões conduzem a questão para o entendimento de que não se pode afirmar que haja uma correspondência total na Lexicografia Interlíngue, mas sim tipos diferenciados, quais sejam, equivalência estilística, pragmática, terminológica, metafórica, etimológica, entre outras.

Palavras-chave: prática lexicográfica; equivalência; dicionário bilíngue.

Abstract: This paper reflects on the lexicographical practice and the issue of equivalence in bilingual dictionaries. It searches in the theoretical assumptions of Bi/Interlingual Lexicography foundations for further understanding of equivalence in the lexicographical bilingual practice. It aims at informing the various types of equivalence that one can aspire 
to in the translation of lexical units from one language A to a language B (WELKER, 2004; HARTMANN, 2007; WERNER; DURÃO, 2012) and at presenting aspects of equivalence under the various looks of some subjects of Applied Linguistics. We believe that the paper can help to clarify the equivalence, one of the translation aspects that, among scholars in the field, is far from a consensus. The reflections lead the issue to the understanding that one cannot say there is total equivalence in the Interlingual Lexicography, but rather, types of different equivalences, namely, stylistic equivalence, pragmatic, terminological, metaphoric, etymological, among others.

Keywords: lexicographical practice; equivalence; bilingual dictionaries.

Recebido em: 3 de março de 2016. Aprovado em: 6 de dezembro de 2016.

As constantes transformações por que passa a sociedade afetam diretamente a língua de uma nação e, em consequência, novos termos são formados e ganham vida na boca do povo ao mesmo tempo em que suscitam dúvidas sobre seus sentidos. O uso frequente faz com que essas novas unidades léxicas sejam incluídas no dicionário e recebam tradução em língua estrangeira. Em nossa pesquisa estamos tendo a oportunidade de investigar, de modo aprofundado, a prática lexicográfica, os traços característicos que marcam os dicionários bilíngues, assim como questões em torno da sempre discutida equivalência. Trata-se de uma tese de doutorado em que se objetiva verificar a (possível) presença de unidades fraseológicas com zoônimos em dicionários bilíngues escolares. $\mathrm{O}$ presente artigo faz recorte de um dos aspectos contemplados no estudo em questão - a discussão sobre a prática lexicográfica e os vários tipos de equivalência na subárea da Lexicografia Bilíngue. Segundo Welker (2004, p. 193), há literatura vasta sobre a Lexicografia Bilíngue, embora seja menos volumosa do que a relativa aos dicionários monolíngues. No entanto, a história da pesquisa em Lexicografia Bilíngue é relativamente breve, se considerarmos a longa data de atuação dos dicionários na vida do homem em sociedade.

Durão (2010, p. 15), ao efetuar uma breve retrospectiva sobre a origem dos dicionários (os protodicionários), relata que eles surgiram a partir da escola suméria, em que monges copistas, ao dar explicações 
sobre as palavras e seus significados nas laterais desses livros, iniciaram os rudimentos do dicionário. Desde a Idade Média até os dias de hoje, com os dicionários eletrônicos e on-line, muitas mudanças ocorreram nesses materiais, mas eles continuam indispensáveis. Sua utilidade é inegável, sobretudo para as pessoas que precisam falar uma língua estrangeira em tempos de globalização e de intercâmbio cultural.

Para a elaboração dos dicionários, os lexicógrafos se valem, na maioria das vezes, dos resultados de pesquisas e procuram adequar esses materiais às diversas funções que eles têm que desempenhar, uma vez que não é possível um dicionário atender a tantas necessidades de utilização, quais sejam, as de recepção e as de produção, que explicitamos na sequência.

Werner e Durão (2012), ao falarem sobre esse fato, afirmam que as dicotomias na bibliografia sobre teoria do dicionário bilíngue se arrastam há muito tempo. Uma das dicotomias está relacionada a duas possíveis funções do dicionário bilíngue - uma ativa e outra passiva. E, de acordo com essas funções, há dois tipos de dicionário - um destinado à recepção e outro à produção de textos. Outra dicotomia refere-se ao fato de que o dicionário bilíngue, caracterizado como dicionário de equivalentes, opõe-se ao dicionário monolíngue, que costuma ser qualificado como dicionário explicativo ou de definições.

Diante da dicotomia mencionada em relação às funções do dicionário, Werner e Durão (2012) entendem que é necessário levar em consideração as distinções existentes entre: (1) os dicionários de consulta como ferramentas para a solução de problemas de recepção ou de produção; (2) os dicionários bilíngues didáticos, concebidos para a aquisição de uma língua que não é a língua materna do usuário, ou para a aprendizagem sistemática de uma língua estrangeira.

É comum se pensar que os dicionários monolíngues são melhores para a aprendizagem de uma língua estrangeira do que os bilíngues, mas, segundo Werner e Durão (2012), "há fortíssimos argumentos em defesa da elaboração e do uso de dicionários bilíngues destinados a falantes de línguas maternas específicas". Aliás, para o produtivo lexicógrafo Welker (2004, p. 194), "há vários aspectos em que os bilíngues diferem muito pouco dos monolíngues" e o que os diferencia, entre outras coisas, é o fato de que "no lugar da definição, são fornecidos equivalentes".

Para a prática lexicográfica no que se refere aos dicionários bilíngues, Werner e Durão (2012) defendem que 
[...] os dicionários bilíngues, muito especialmente os que têm função didática, não devem ser concebidos, em primeiro lugar, como dicionários de equivalências, mas devem ser planejados como dicionários contrastivos, ou seja, devem destacar não a equivalência entre as expressões da língua de partida e as da língua de destino que compartilhem traços formais, semânticos e pragmáticos com aquelas, mas proporcionar ampla informação diferenciadora. Dicionários deste tipo seriam sumamente úteis no caso de línguas genética e estruturalmente próximas, especialmente quando se trata de dicionários de aprendizagem.

Os dicionários do tipo contrastivo, especialmente os dicionários de aprendizagem, podem proporcionar a instrução lexicográfica e aproveitar as afinidades interlinguais, ou seja, em dicionários contrastivos pode-se dar atenção maior à transferência positiva ou negativa dos elementos linguísticos de uma língua a outra, seja da língua materna para a estrangeira ou, ainda, para uma segunda ou terceira língua adquirida que tenha estruturas parecidas. Nesse sentido, esses dicionários são muito úteis e necessários para a aprendizagem de línguas e/ou para o processo de tradução.

\section{A Lexicografia Interlíngue e o processo de tradução}

Na Linguística, pode-se considerar o processo de tradução uma operação interlinguística fascinante. Para Hartmann (2007, p. 12), a Linguística, a Filosofia, a Antropologia, a Sociologia, assim como o aluno de literatura, o professor de língua, o engenheiro de comunicação têm contribuição a dar no sentido de ajudar a perceber como a língua funciona, mas só o linguista pode trazer para o estudo da língua o devido entendimento acerca da complexidade das muitas facetas que envolvem os processos tradutórios.

Há que se acrescentar que se tem desenvolvido a compreensão de processos elementares da tradução em virtude de uma maior interação entre tradutores, linguistas, engenheiros de computação, missionários, especialistas de documentação, professores de línguas, filósofos e outros. Pode-se pensar em vários tipos de tradução (a simultânea, a escrita, a automática) para a área das línguas estrangeiras e em vários estágios para 
o processo de traduzir (leitura do texto original, escolha do vocabulário, preparação de um primeiro rascunho, conferência, revisão). Nesse processo procura-se reproduzir, ao máximo, características e marcas da língua de partida. Como diz Hartmann (2007, p. 13, tradução nossa),

[...] o objetivo é reproduzir tão corretamente quanto possível todas as características lexicais e gramaticais da língua fonte original encontrando equivalentes apropriados na língua de chegada, e que, às vezes é mais importante reter a informação factual, e às vezes a ênfase é sobre a forma. ${ }^{1}$

A tradução na Lexicografia Interlíngue tem se mostrado produtiva. Tem-se categorizado e classificado alguns tipos de textos, utilizandose a teoria da informação e incorporando-se os chamados fatores extralinguísticos como "o assunto, o tempo e o lugar a que o texto se refere, alguma conexão pessoal do autor e leitor etc."’2 (HARTMANN, 2007, p. 13, tradução nossa). Apesar de um texto poder ser descrito por meio da análise de seus componentes gramaticais, lexicais e grafêmicos, ainda assim há que se levar em consideração os fatores extralinguísticos a fim de poder harmonizar tais componentes e o conteúdo da passagem. Para a análise lexicológica do vocabulário de algumas línguas, a Lexicografia se mostra útil e, com isso, uma grande quantidade de dicionários tem atendido aos usuários especializados. Análises feitas no campo da Lexicografia $\mathrm{Bi} /$ Interlíngue têm igualmente se servido dos princípios da Linguística Contrastiva, que tem contribuído para os avanços da área na resolução de problemas de tradução. O processo de tradução obedece a algumas etapas que podem ser reconhecidas no trabalho do dia a dia do tradutor, do lexicógrafo. Hartmann (2007, p. 14) sintetiza as operações sucessivas pelas quais passa o processo de tradução:

\footnotetext{
1 "We know that the aim is to reproduce as accurately as possible all grammatical and lexical features of the source language original by finding suitable equivalents in the target language, and that sometimes it is more important to retain the factual information, sometimes the emphasis is on form [...]".

2 "Namely the subject matter, the time and place to which the text refers any personal attachments of author and reader [...]".
} 
(i) ler o texto original;

(ii) organizar vocabulário desconhecido e conseguir informação através de corpus paralelos;

(iii) esboçar a primeira versão;

(iv) conferir a versão comparando-a ao original e buscar referência nos especialistas;

(v) escrever a versão final com atenção especial ao estilo e à língua alvo dos leitores.

Alguns tradutores profissionais podem estabelecer categorias diferentes de tradução, quando se trata de tradução literária ou pragmática, porém as etapas sugeridas por Hartmann (2007) podem demonstrar alguns dos procedimentos seguidos para se chegar à equivalência no processo de tradução. A busca pela equivalência pode fazer com que o tradutor, o pesquisador ou o aprendiz de língua estrangeira incorram, muitas vezes, em uma verdadeira problemática com relação à decisão a ser tomada nesse processo.

\section{A problemática da equivalência na prática lexicográfica}

Quando buscamos a equivalência nos dicionários bilíngues, geralmente estamos motivados pela tentativa de entendermos melhor o que lemos. No entanto, quando nosso objetivo é o de escrever um texto ou o de verter porções de nossa língua materna para a língua estrangeira, isso se torna bem mais difícil. Encontrar o modo como devemos expressar certas sequências escritas na língua estrangeira requer um material de consulta que ofereça bem mais do que um sinônimo ou uma forma correspondente. Aliás, a questão é discutida por vários linguistas e lexicógrafos, mesmo porque qualquer equivalência fornecida, sem contextualização, acaba por deixar o aprendiz inseguro para utilizá-la em sua produção ou o tradutor incerto se fez a melhor escolha para o texto vertido.

Para o lexicógrafo Hartmann (2007, p. 15), o problema da equivalência na Lexicografia Bilíngue precisa ser analisado pelas lentes de pelo menos quatro disciplinas da Linguística Aplicada (LA): a Linguística Contrastiva, a Teoria da Tradução, a Análise de Erro e a Aprendizagem de Vocabulário. A seguir, especificamos a problemática da equivalência segundo as vertentes citadas. 


\subsection{Pelo olhar da Linguística Contrastiva}

Com vistas a explicitar o problema da equivalência conforme a Linguística Contrastiva, Hartmann (2007, p. 15) cita Zgusta (1971, p. 294), que desenvolveu a noção conhecida como "aisomorfismo" semântico e cultural, o que levou a estudos mais sistemáticos da Lexicologia Contrastiva. Para entendermos melhor o conceito, o dicionário nos informa que isomorfismo é a "semelhança entre formas que permitem uma relação de correspondência" (ISOMORFISMO, 2003-2017), e, nesse sentido, o que Zgusta (1971 apud HARTMANN, 2007) quer dizer com o termo aisomorfismo é que é impossível uma correspondência semântico-cultural total.

Snell-Hornby (1983, p. 247 apud HARTMANN, 2007, p. 15), por sua vez, desenvolve o conceito de equivalência mostrando-se cética com relação a uma equivalência única e afirmando que não se deve confiar "na ilusão de equivalência entre lexemas, mas na percepção de que a cobertura parcial e a não equivalência são uma realidade da comparação interlinguística"' (SNELL-HORNBY, 1983, p. 247 apud HARTMANN, 2007, p. 15, tradução nossa). A autora sugere uma subdivisão em várias classes que vão dos dois extremos entre a 'equivalência total' até 'nenhuma correspondência' para explicar a equivalência. Essa gradação é também chamada de "continuum entre dois extremos" pelo lexicógrafo e tradutor Nida (1964 apud HARTMANN, 2007, p. 14) (cf. Fig. 1).

Figura 1. A equivalência vista em um continuum da comparação interlingual
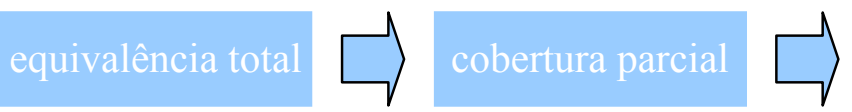

não equivalência

Muitas são as discussões em torno da metodologia que envolve a análise contrastiva e o estudo da equivalência. Apesar de criticar a validade dessa metodologia aplicada à prática lexicográfica bilíngue, ainda assim, Hartmann (2007, p. 15, tradução nossa, grifos nossos) ressalta que:

\footnotetext{
3 "Not on the illusion of equivalence among lexemes, but on the awareness that partial coverage and non-equivalence are a reality of interlingual comparison".
} 
Não há metodologia consistente, o trabalho é frequentemente desigual, parcial, intuitivo, arbitrário e experimental, e dessa forma de potencial gerador limitado (que é particularmente verdadeiro para alguns argumentos acerca do 'campo semântico'). Raramente há critério confiável para testar a validade das anotações usadas, e quase nunca os achados podem ser aplicados para prever ou resolver problemas. Por exemplo, longe de afetar o trabalho do lexicógrafo, tais estudos comparativos seriam bem difíceis sem a ajuda dos dicionários bilingues! Frequentemente tais estudos carregam um sentimento de irrealidade e artificialidade. Palavras são simplificadas, vistas isoladamente, desvestidas de todos os seus contextos colocacionais, inflexionais e derivacionais, tomadas de seus ambientes da vida real. A equivalência lexical permanece correspondência estática de palavras em níveis ou graus estruturais estipulados. ${ }^{4}$

A crítica de Hartmann (2007, p. 15) é procedente; no entanto, o autor admite otimismo nos estudos com textos paralelos que vêm sendo desenvolvidos na Linguística de Texto, com a combinação de abordagens comparativo-contrastivas que recomendam o confronto das estratégias textuais para os pares de línguas como um meio de ampliar o escopo da Linguística Contrastiva. Em meio a esses estudos pode-se contar com outra área da Linguística Aplicada em que se desenvolvem pesquisas sobre a atividade tradutória - a Teoria da Tradução.

\footnotetext{
4 "There is no consistent methodology, the work is often patchy, partial, intuitive, arbitrary and tentative, and thus of limited generalizability (which is particularly true of some claims about the 'semantic field'). There are rarely reliable criteria for testing the validity of notations used, and hardly ever can the findings be applied to predict or solve problems. For example, far from affecting the work of the lexicographer, such comparative studies would be very difficult without the help of bilingual dictionaries! Frequently such studies convey a feeling of unreality and artificiality. Words are abstracted, seen in isolation, shorn of all their derivational, inflectional and collocational context, taken out of their real-life discourse settings. Lexical equivalence remains static correspondence of words at stipulated structural levels or ranks".
} 


\subsection{Pelo olhar da Teoria da Tradução}

A tradução, segundo Hartmann (2007, p. 16, tradução nossa), "não é mais vista como palavras que se combinam em compartimentos particulares dentro das hierarquias gramaticais correspondentes, mas como um processo dinâmico de aproximação, relacionando textos inteiros a seus contextos comunicativos". ${ }^{5}$ Por conseguinte, os teóricos na atualidade não estão preocupados em classificar as correspondências, mas, ao invés disso, preocupam-se em identificar as condições presentes para poder chegar à equivalência. $\mathrm{O}$ lexicógrafo avalia que a análise lexical pode explicar alguns fenômenos divergentes e convergentes entre os itens, mas ela não pode resolver outras dificuldades que o tradutor venha a ter.

Na tentativa de conhecermos um pouco mais o dicionário bilíngue, a prática lexicográfica e os equivalentes, podemos perguntar: "O que fazer, então, quando não encontramos um equivalente literal"? Hartmann (2007, p. 16) responde que se pode seguir certo número de procedimentos de tradução para se fazer uma "substituição aceitável, tal como empréstimo, paráfrase explicativa, ou outras formas de adaptação"' (HARTMANN, 2007, p. 16, tradução nossa). O autor enfatiza que a tradução não é um código morto e que o tradutor (como um mediador bilíngue) lida com a mudança de código ativa, compelido pela natureza do texto e por seus próprios "níveis individuais de proficiência linguística e conhecimento enciclopédico"” (HARTMANN, 2007, p. 16, tradução nossa).

Isso posto, qual é a relevância da Teoria da Tradução para a elaboração das equivalências tradutórias no dicionário bilíngue e no contexto de ensino da língua estrangeira? A relevância repousa no fato de que equivalentes empregados rotineiramente na prática de tradução profissional e pedagógica acabam por ser inseridos nos manuais de ensino e no dicionário bilíngue. Dessa forma, a importância do dicionário bilíngue é a de que ele é um "repositório das equações coletivas

\footnotetext{
5 "Translation is no longer seen as matching words at particular slots within corresponding grammatical hierarchies, but as a dynamic process of approximation, relating whole texts to their communicative contexts".

6 "a suitable substitution, such as borrowing, explanatory paraphrase, or other forms of adaptation".

7 “[...] but also by their individual levels of linguistic proficiency and encyclopedic knowledge".
} 
estabelecidas por gerações de "lexicógrafos tradutores"”. (HARTMANN, 2007, p. 16, tradução nossa). Ainda que se encontrem muitas falhas nesse material, especialmente no aspecto da equivalência, são inegáveis os benefícios que sua utilização pode trazer para a prática lexicográfica, para o ensino e para a aprendizagem de línguas. Na aprendizagem é comum a ocorrência de erros pelo aprendiz e essa tendência pode ser estudada por meio da análise de erro.

\subsection{Pelo olhar da Análise de Erro}

A disciplina da LA que se preocupa em detectar e estudar expressões incorretas na aprendizagem de língua estrangeira é a Análise de Erro. Por meio dela, procura-se descobrir as motivações que desencadeiam as divergências entre as línguas, entre as equivalências, das palavras da língua fonte com as palavras da língua alvo. Hartmann (2007, p. 18, tradução nossa) questiona se no momento da tradução "a troca para frente e para trás leva a interferência [...]". ${ }^{9}$ Conforme o aprendiz vai construindo as frases na língua estrangeira à medida que vai pensando em sua própria língua, acaba por incorrer em um processo de tradução literal palavra por palavra. Dessa forma, o aprendiz, muitas vezes, tem a propensão de elaborar construções estranhas do tipo "a água está cozinhando", quando pretenderia dizer "a água está fervendo". Assim ele incorre no fenômeno da interferência que não pode ser prevista, conforme comprovam os estudos de Nemser e Vincenz (1972 apud HARTMANN, 2007, p. 18). Para eles, "o processo de aquisição dos equivalentes lexicais é, de fato, muito complexo. Até mesmo aprendizes avançados e bilíngues cometerão erros inevitáveis desse tipo"10 (NEMSER; VINCENZ, 1972 apud HARTMANN, 2007, p. 18, tradução nossa).

Hartmann (2007, p. 18) aconselha que se criem contextos de aprendizagem que facilitem o desenvolvimento de estratégias de aproximação, pois os erros lexicais acontecem porque "os equivalentes não ocorrem em pares fixos, estáticos, mas têm que ser aproximados e

\footnotetext{
8 “"[...] repository of the collective equations established by generations of 'translating lexicographers"”.

9 "Does switching back and forth lead to interference $[. .$.$] ?"$

10 "The process of acquiring lexical equivalents is very, complex indeed. Even advanced learners and proficient bilinguals will commit unavoidable errors of this kind."
} 
exercitados novamente para quase todo novo contexto" "HARTMANN, 2007, p. 18, tradução nossa). Sabemos que é comum os aprendizes fazerem frases "estranhas" quando tentam juntar unidades léxicas pelo seu significado denotativo, posto que, na maioria das vezes, desconhecem as colocações que acompanham essas palavras. E a construção ao acaso vai provocar frases não usuais na língua alvo. $\mathrm{O}$ estudo das unidades lexicais e a tentativa de se entender melhor a ampliação e aprendizagem de vocabulário têm recebido impulsos significantes na área dos estudos do léxico e da busca pelas equivalências.

\subsection{Pelo olhar da Aprendizagem de Vocabulário}

Na aprendizagem do vocabulário importa desenvolver estratégias linguísticas que auxiliem o aprendiz em sua busca por equivalentes. No processo de busca de equivalentes para concretizar a conversação ou a tradução é comum se procurar simplificar ou preencher o vazio semântico com estratégias de tradução. Para os pesquisadores BlumKulka e Levenston (1983 apud HARTMANN, 2007, p. 19), algumas das estratégias de tradução são: (a) o uso de termos superordenados; (b) a aproximação; (c) o uso de sinônimos; (d) a transferência; (e) a circunlocução e a paráfrase.

O uso de termos superordenados é comum no processo de construção de definição do dicionário e se trata de substituir uma palavra que falta por outra que está acima na hierarquia semântica - se não se sabe, por exemplo, a palavra ferver, usa-se seu hiperônimo cozinhar -, ou por uma que está abaixo (hipônimo) - como substituir apurar por ferver lentamente (HARTMANN, 2007, p. 19).

A estratégia de aproximação é a da substituição da expressão desconhecida por outra do contexto, nem sempre tão próxima da palavra que se quer. Hartmann (2007, p. 19) exemplifica essa estratégia com o caso da aproximação da palavra mesa (desconhecida do aprendiz) a jantar self-service. Apesar de parecer distante, é uma estratégia possível para o aprendiz, pois o jantar se coloca em uma mesa; por isso dizerse que é uma estratégia de aproximação. Já o uso de sinônimos é uma estratégia comum em que se utiliza uma palavra conhecida no lugar

\footnotetext{
11 "Equivalents do not occur in fixed, static pairs, but must be approximated and practiced afresh for almost every new context".
} 
daquela que se desconhece, como, por exemplo, usar homem bonito em vez de homem lindo.

Para Hartmann (2007, p. 19), a transferência é o processo em que se utilizam palavras da língua materna para substituírem uma palavra da língua estrangeira que não se conhece. É usual o aprendiz utilizar um (falso) cognato, que ele pensa ter o mesmo significado na outra língua, ou ainda "forçar" uma palavra de sua própria língua com traços da língua alvo (principalmente a pronúncia), ou mesmo usar a palavra da língua fonte sem modificações. É uma estratégia bastante empregada pelos iniciantes e teve seu momento de glória durante a fala do técnico de futebol da África do Sul, Joel Santana, que ficou eternizada em uma entrevista concedida durante a Copa das Confederações de 2009, por seu inglês "embromation", pela característica peculiar de aportuguesar o inglês falado (cf. JOEL..., 2013). Apesar de ser algo explorado pela mídia, pela comicidade, é estratégia natural e corrente de aprendizes iniciantes.

Há, ainda, segundo Hartmann (2007, p. 19), a estratégia conhecida por circunlocução, quando o aprendiz rodeia um assunto sem ir direto ao ponto, às vezes até usando frases repetidas sem conseguir encontrar a palavra que precisa na língua alvo; e, por fim, a paráfrase, em que se toma um caminho indireto na comunicação para se tentar chegar ao equivalente. $\mathrm{O}$ aprendiz, por não saber a unidade lexical que quer empregar na língua alvo, busca dar explicações sobre a utilidade do objeto ao qual precisa se referir, na tentativa de encontrar seu equivalente. Além dessas, a criação de palavras e a mudança de assunto são também estratégias que podem ser usadas pelo aprendiz de línguas estrangeiras na tentativa de preencher o vazio semântico existente.

Dessa forma, no que diz respeito ao estabelecimento de equivalência nos dicionários bilíngues, várias abordagens são possíveis: a Linguística Contrastiva para identificar o vocabulário nos pares de línguas, a Teoria da Tradução para classificar tipos de equivalência, a Análise de Erros para verificar a variabilidade do processo, e o Ensino de Vocabulário para prover contexto para as estratégias de aproximação. As reflexões de Hartmann (2007, p. 19) levam-no a dizer que está convicto de que a Análise Contrastiva, combinada com estratégias bilíngues de comunicação, pode se tornar ferramenta útil para o refino da prática lexicográfica. Na sequência, listamos alguns exemplos que demonstram tipos ou graus de equivalência no processo de tradução. 


\section{Os vários graus de equivalência}

Nesta sessão objetivamos dar a conhecer alguns tipos de equivalência que podem ser almejados na tradução de unidades léxicas de uma língua A para uma língua B (WELKER, 2004; HARTMANN, 2007; WERNER; DURÃO, 2012) e apresentar aspectos dos vários graus de equivalência, pois que são abundantes. Sublinhamos, contudo, que foge ao escopo deste artigo pormenorizar todos eles. Citamos os resumos que Welker (2004, p. 195) e Carvalho (2001, p. 113 et seq.) fazem de um dos graus de equivalência, que seria a ausência de equivalência. Welker (2004, p. 195) e Carvalho (2001, p. 117), baseando-se em Schnorr (1986, p. 56-60), explicam que a ausência de equivalência pode ocorrer principalmente nas seguintes áreas: atividades e festividades, vestuário, utensílios, fatos históricos, comidas e bebidas, religião, educação e outras áreas especializadas. A seguir, exemplificamos com base em Carvalho (2001, p. 118) algumas das estratégias (com o par de línguas alemãoportuguês e inglês-português) para solucionar problemas da ausência de equivalência, como, por exemplo:

- empréstimo: interventor (alemão) - Interventor + explicação (português);

- decalque: tradução literal, "tradução-cópia”; Bundesrat (alemão) - Conselho Federal (português);

- item lexical análogo: um item lexical da L2 designa um objeto ou fato análogo ao objeto ou fato designado pelo item lexical da L1; Welfare Department (inglês) - INSS (português);

- paráfrase: Bastler (alemão) - pessoa que gosta de executar tarefas manuais (paráfrase).

Os exemplos citados são possíveis soluções que podem ser apresentadas para o problema da ausência de equivalentes. Nesse sentido, para uma equivalência "total", muitos aspectos precisam ser revistos, pois não basta a correspondência simples dos sememas de A (L1) com os de B (L2). Concordamos com Welker (2004, p. 196), que afirma que, para se alcançar a equivalência total, há que se buscarem outros graus de equivalência ou combinação. Exemplificamos: 
- $\quad$ estilística (mesmo registro) - se usada uma expressão coloquial, com nuances informais, precisa-se manter o mesmo registro;

- $\quad$ pragmática - o equivalente deve poder ser usado nas mesmas situações de comunicação. Espera-se que a equivalente de uma expressão idiomática na língua de origem seja também uma expressão idiomática que expresse o sentido que se quer na língua alvo;

- terminológica - um termo técnico deve ser traduzido por um termo técnico na L2;

- diacrônica - um lexema antiquado deve ser traduzido por um lexema antiquado na L2;

- contextual - o equivalente deve poder ser usado em co(n)textos semelhantes;

- $\quad$ sintático-gramatical - o equivalente deve poder ser usado nas mesmas estruturas sintáticas, por exemplo, na voz passiva;

- metafórica - uma metáfora deve ser traduzida por uma metáfora;

- $\quad$ etimológica - devem-se preferir equivalentes que têm a mesma origem do lexema da L1;

- formadora de palavras - política, político (politics, politician inglês);

- frequente - os equivalentes devem ter, nas duas línguas, o mesmo nível de frequência de uso;

- fonética-prosódica - importante em textos literários;

- diatópica - praticamente impossível de ser alcançada, pois não faz sentido traduzir um regionalismo da L1 por um regionalismo (com conotações bem diferentes) da L2.

Depreendemos, pelos exemplos mencionados, que dificilmente as traduções vão poder cumprir todos os tipos de equivalência, e esse é um dos motivos de termos colocado a expressão total entre aspas, uma vez que, na prática lexicográfica, os vários fatores que urgenciam o trabalho do lexicógrafo (prazos apertados, espaço limitado de páginas, necessidade de fazer algo rentável, várias funções a que o dicionário está sujeito, ativa ou passiva, e muitas outras exigências) acabam por pressioná-lo e não 
dão a ele as condições ideais para que busque a equivalência "total" das unidades léxicas e persiga os vários tipos de equivalência. Ainda assim, deve-se insistir para que um bom dicionário bilíngue apresente o maior número possível dos tipos de equivalência, posto que essa é a verdadeira natureza da prática lexicográfica.

\section{Considerações finais}

No início do artigo nos propusemos a refletir sobre a prática lexicográfica e a problemática da equivalência em dicionários bilíngues. Baseando-nos pressupostos teóricos da Lexicografia Bi/Interlíngue, expusemos alguns fundamentos que pretenderam ampliar o entendimento da equivalência na prática lexicográfica bilíngue. Apresentamos os vários tipos de equivalência que podem ser buscados na tradução de uma língua A para uma língua B com base em Welker (2004), Hartmann (2007) e Werner e Durão (2012), entre outros, e comentamos aspectos da equivalência sob os olhares de algumas disciplinas da Linguística Aplicada. Buscamos esclarecer a equivalência, um dos aspectos da tradução que, segundo os estudiosos da área, está longe de ser um consenso. As reflexões feitas à luz das teorias explicitadas nos levam a afirmar que não há uma equivalência "total" na Lexicografia Interlíngue, mas sim tipos diferenciados, quais sejam, a estilística, a pragmática, a terminológica, a metafórica, a etimológica, entre outras.

A prática lexicográfica referente aos materiais bilíngues, os tão valiosos dicionários, carece de estudos constantes e observância frequente de resultados de pesquisas atualizados, uma vez que tratam de um objeto que é dinâmico e mutável por natureza: a língua que falamos, a língua que traduzimos.

\section{Referências}

BLUM-KULKA, S.; LEVENSTON, E. Universals of lexical simplification. In: FAERCH, C.; KASPER, G. (Ed.). Strategies in interlanguage communication. London; New York: Longman, 1983. p. 119-140 apud HARTMANN, R. R. K. Interlingual Lexicography. Tübingen: Max Niemeyer Verlag, 2007.

CARVALHO, O. L. de S. Lexicografia bilíngue português-alemão: teoria e aplicação à categoria das preposições. Brasília: Thesaurus, 2001. 
DURÃO, A. B. A. B. Seguindo os rastros do dicionário. In: (Org.). Vendo o dicionário com outros olhos. Londrina: UEL, 2010. p. 15-28. HARTMANN, R. R. K. Interlingual Lexicography. Tübingen: Max Niemeyer Verlag, 2007.

ISOMORFISMO. In: DICIONÁRIO Infopédia da língua portuguesa com Acordo Ortográfico. Porto: Porto Editora, 2003-2017. Disponível em: $<$ http://www.infopedia.pt/dicionarios/lingua-portuguesa/isomorfismo $>$. Acesso em: 21 fev. 2016.

JOEL Santana e seu inglês brilham em comercial de xampu. UOL Esporte, 16 jul. 2013. Blog da Redação. Disponível em: <http://uolesporte. blogosfera.uol.com.br/2013/07/16/joel-santana-e-seu-ingles-brilhamem-comercial-de-xampu/>. Acesso em: 26 fev. 2016.

NEMSER, W.; VINCENZ, I. The indeterminacy of semantic interference. Revue Roumaine de Linguistique, Bucuresti, Editura Academiei, v. 17, n. 2, p. 99-120, 1972 apud HARTMANN, R. R. K. Interlingual Lexicography. Tübingen: Max Niemeyer Verlag, 2007.

NIDA, E. A. Towards a science of translating. Leiden: E. J. Brill, 1964 apud HARTMANN, R. R. K. Interlingual Lexicography. Tübingen: Max Niemeyer Verlag, 2007.

SNELL-HORNBY, M. Verb-descriptivity in German and English. A contrastive study in semantics fields. Heidelberg: Winter, 1983 apud HARTMANN, R. R. K. Interlingual Lexicography. Tübingen: Max Niemeyer Verlag, 2007.

WELKER, H. A. Dicionários - uma pequena introdução à Lexicografia. Brasília: Thesaurus, 2004.

WERNER, R; DURÃO, A. B. A. B. Dicionários bilíngues de línguas afins. Conferência de Abertura do I Simpósio Internacional de Lexicografia e Linguística Contrastiva (SILLIC), Florianópolis, 3 dez. 2012. Florianópolis: UFSC, 2012. Vídeo (84 min. $33 \mathrm{seg}$.), 499,8 Mb, formato FLV. Disponível em: <https://repositorio.ufsc.br/ handle/123456789/104816>. Acesso em: 21 fev. 2016.

ZGUSTA, L. Manual of Lexicography. Paris: Mounton, 1971 apud HARTMANN, R. R. K. Interlingual Lexicography. Tübingen: Max Niemeyer Verlag, 2007. 